\title{
Algumas questões filosóficas envolvendo a doutrina das pulsões na obra freudiana
}

\author{
Some philosophical issues involving the doctrine of drives in Freudian work
}

Eduardo Ribeiro da Fonseca

Doutor em Filosofia Moderna e Contemporânea pela Universidade de São Paulo (USP), escritor e tradutor, professor de Filosofia da Pontifícia Universidade Católica do Paraná (PUCPR), Curitiba, PR - Brasil, e-mail:

eduardorfonseca@uol.com.br

Recebido: $19 / 12 / 2013$

Received: 12/19/2013

Aprovado: 07/04/2014

Approved: 04/07/2014

\section{Resumo}

A doutrina das pulsões, que começou a ser gestada na obra de Schopenhauer, foi, depois, ampliada, em certa medida contestada, adquirindo novas e surpreendentes nuances na obra de Nietzsche. Por fim, tornou-se assumidamente o núcleo da teoria da psicanálise de Freud. Porém, passados quase duzentos anos, ela ainda hoje é um desafio para o psicanalista contemporâneo na medida em que é um estudo fronteiriço entre aquilo que é eminentemente natural e aquilo que, dessa suposta natureza, se modificou para se traduzir em ser humano. 0 texto a seguir desenvolve alguns novos aspectos da pesquisa que resultou no livro Psiquismo e vida: Sobre a noção de Trieb nas obras de Freud, Schopenhauer e Nietzsche (2012).

Palavras-chave: Pulsão. Inconsciente. Vontade.

\begin{abstract}
The doctrine of drives (Triebe), which began to be gestated in the work of Schopenhauer, was later expanded, and to a certain extent, contested, and acquired new and surprising nuances in Nietzsche's work. At last, it admittedly became the core of Freud's theory of psychoanalysis. However, after almost two hundred years, it is still a challenge for the contemporary psychoanalyst to the extent that it is a borderline study between what is eminently natural and what, of this supposed nature, has changed to be translated into human beings. The following text develops some new aspects of the research that resulted in the book Psychism and Life: On the notion of Trieb in the works of Freud, Schopenhauer and Nietzsche (2012).
\end{abstract}

Keywords: Drive. Unconcious. Will. 


\section{"Nunca os torturou o medo de ser completamente inaptos Para reconhecer o que é verdadeiro?"}

(Nietzsche, Aurora)

A doutrina das pulsões, que começou a ser gestada na obra de Schopenhauer, foi depois ampliada, em certa medida contestada, e adquiriu novas e surpreendentes nuances na obra de Nietzsche. Por fim, tornou-se assumidamente o núcleo da teoria da psicanálise de Freud. Porém, passados quase duzentos anos, ela ainda hoje é um desafio para o psicanalista contemporâneo, na medida em que é um estudo fronteiriço entre aquilo que é eminentemente natural e aquilo que dessa suposta natureza se modificou para se traduzir em ser humano. 0 texto a seguir desenvolve alguns novos aspectos da pesquisa que resultou no livro Psiquismo e vida: Sobre a noção de Trieb nas obras de Freud, Schopenhauer e Nietzsche (2012).

\section{Além-do-homem estava no passado}

Em Psicologia de massas e análise do eu (1921), a mítica personagem do além-do-homem é situada na posição de patriarca da horda primitiva, pois unicamente ela, segundo Freud, apresentaria uma psicologia individual, que viria associada ao poder inconteste, enquanto para o grupo restaria a obediência (em parte pela brutalidade do comando, em parte pela sugestão hipnótica vinculada ao funcionamento primitivo das massas humanas).

Nesse modelo da origem da sociedade, o patriarca é o indivíduo originário e a sua memória, ao longo de gerações, confere-lhe características divinas. "Nos primórdios da história humana, o patriarca da horda primitiva foi o além-do-homem, cujo aparecimento esperava Nietzsche para o distante futuro" (Freud, 1920). As características desse senhor patriarcal são definidas do seguinte modo: "Ele não necessita amar a ninguém, pode tornar-se dono e senhor e, sendo totalmente narcisista, acha-se seguro de si mesmo e goza de completa independência".

Freud faz aqui o papel de intermediário entre Nietzsche e Schopenhauer na medida em que expõe as dificuldades inerentes ao fato de que tal indivíduo, em sua total independência, não precisa se identificar com ninguém, não necessita de compaixão, e a oferece como concessão ligada à sua necessidade prática, à sua política (temos um claro resquício disso no coronelismo brasileiro): "Sabemos que o narcisismo limita o amor, e poderíamos demonstrar que atuando assim, constituiu-se como um importante fator civilizatório" (Freud, 1920). Tal fator civilizatório resulta do fato de que o pai da horda primitiva não era imortal, como depois chegou a ser por divinização, e, desse modo, alguém teve que ocupar o seu lugar. 0 que isso sugere? Sugere a hipótese de que deve existir uma possibilidade de transformar a psicologia de grupo em psicologia individual, o que é reforçado pela observação natural, pois, de modo análogo, o mesmo ocorre entre formigas e abelhas, que em caso de necessidade fazem surgir dentre as larvas uma rainha no lugar de uma operária.

Do ponto de vista do organismo humano, tal transformação encontra sua justificativa nos modos de satisfação dos impulsos sexuais. Segundo Freud, o pai primitivo impedia que seus filhos obtivessem a satisfação de suas tendências sexuais diretas, lhes impunha a abstinência, e, por conseguinte, a título de derivação, estabelecia também os laços afetivos que os ligavam à psicologia coletiva. A psicologia de massas não é, em última análise, senão um produto da sexualidade irrestrita do patriarca e de sua intolerância para com os outros.

Seguindo essa linha de raciocínio, a hipótese sobre o parricídio resulta da consideração de que filhos expulsos da horda passaram da identificação recíproca à eleição de objeto homossexual, conquistando assim sua liberdade, o que lhes permitiu matar o pai. Todas as organizações sociais atuais parecem ser derivadas desse protótipo primitivo que se baseia no amor e poder paternos, e na culpa pelo seu assassinato, por outro. Portanto, o poder corporativo de nossa época atual não passaria de um desdobramento e refinamento dessa situação primitiva.

Em Moisés e o monoteísmo repete-se o mesmo esquema, dessa vez associado à figura do fundador da cultura judaica. 0 monoteísmo é uma cultura religiosa, segundo Freud, expatriada do Egito, onde não vingou: "Se Moisés era egípcio e se transmitiu aos judeus sua religião, esta era a de Akhnaton, a religião de Aton" (Freud, 1939). ${ }^{1}$

1 Akhenaton, cujo nome inicial foi Amen-hotep (que significa "Amon está satisfeito") IV (ou, na versão helenizada, Amenófis IV), foi um grande faraó da XVIII Dinastia 
Esta, ao se impor entre os judeus, impôs também severas restrições à liberdade humana. A angústia e o ressentimento que se originam dessas relações definiram as características da civilização ocidental através de um estilo de recalque que, para Freud, expressa uma forma de psicologia individual e uma forma de psicologia de grupo, que nos termos nietzschianos poderia ser traduzido pelas noções de psicologia do senhor e psicologia do escravo, extensamente analisadas no polêmico texto Genealogia da moral.

A visão freudiana do além-do-homem contraria a forma como o autor do Zaratustra articula o conceito? Em parte sim, na medida em que Freud situa no passado algo que para Nietzsche estaria no futuro, o que implica também no fato de que Freud via nessa imagem apenas uma forma de onipotência humana baseada num modelo social específico e

egípcia. Em seu reinado de 17 anos, rompeu com todo o sacerdócio e o culto dos deuses tradicionais, para impor um deus único ao Egito, representada no disco solar de Aton. Justificava a instituição deste culto sob a alegação de que o Sol ilumina e aquece o mundo inteiro. No entanto, a historiografia sugere que tenha feito isso para concentrar o poder na figura divinizada do faraó (único intermediário de Aton) e, consequentemente, para retirar o poderio dos sacerdotes dos antigos deuses caídos. 0 rei tomou o nome de Akhenaton, aquele que é útil a Aton. Assim, fechou os templos tradicionais e mandou construir santuários de Aton em todo o Egito. Fundou uma nova capital a 300 quilômetros ao norte da antiga e deu-lhe o nome de Akhetaton, que significa espírito atuante de Aton. Construiu o templo principal de Aton, do qual o faraó ficou sendo o grão-sacerdote. Mas, o culto não teve aderência, especialmente porque muito poucos se beneficiaram com a mudança. A maioria, pelo contrário, ressentiu-se tanto da perda da tradição anterior e dos hábitos a ela ligados, como também do ponto de vista político, pois o preço pago pelas mudanças empobreceu o povo. Sucederam-se revoltas e, depois de algum tempo, ocorreu a morte do faraó em 1334 a. C., cujas causas diretas são desconhecidas. Com a retomada dos costumes antigos, Akhenaton foi amaldiçoado. A sua memória, bem como a do deus Aton, foram eliminados como se nunca tivessem existido e foi retomada a religião tradicional. Os templos de Amon recuperaram os seus domínios. A influência de Akhenaton se estende às representações pictóricas, à poesia e à organização social que modificaram não apenas a sociedade egípcia, mas a própria história do mundo com a introdução do monoteísmo, que serve de base à discussão freudiana mencionada aqui. numa característica psicológica do ser humano primitivo que explicaria as características observadas nos indivíduos da sociedade atual. Nesse sentido, a contrapartida contemporânea para Totem e Tabu e Moisés e o Monoteísmo seria Psicologia de Massas e Análise do Eu.

Mas, analisemos a questão sob outros aspectos. Em Nietzsche, as resistências inconscientes são pensadas como fenômenos de proporção entre impulsos e as restrições são necessárias para a geração do tipo excepcional, exatamente como o psicanalista escreve quando articula o conceito de recalque. Mas não é que a civilização seja originada do recalque em si, mas sim da sublimação e da sintomatologia que resultam daquela situação, por força do retorno do recalcado. As oposições mútuas são entendidas por Nietzsche como necessárias e até desejadas para afirmação da potência orgânica, conforme podemos observar especialmente em sua obra não publicada. ${ }^{2}$

Seguindo este fio condutor, se a afirmação unilateral do indivíduo equivalesse à afirmação de um único impulso, isso seria apenas sintomático, pois eliminaria o caráter do jogo entre potências, o fort- $d a$ das potências. Esse é um elemento importante e ressaltado no texto intitulado Crepúsculo dos ídolos. Do mesmo modo, a interpretação de Freud do Übermensch (além-do-homem) parece tomá-la sem esse tipo de nuance e deve ser remetida à recepção da sua contemporaneidade em relação a Nietzsche, que o confunde com um filósofo do totalitarismo. Tal interpretação ignora o elogio de Nietzsche ao mundo grego exatamente pela visão de que ali é privilegiada a disputa, e não a vitória a qualquer preço. 0 herói grego é leal ao espírito da luta, que exige que o adversário não seja suprimido. Tanto é assim que, em Nietzsche, o adoecimento é entendido no contexto do predomínio excessivo de tendências hegemônicas. É só nos estados em que a relação entre grupos de impulsos se coloca em desproporção é que surge o aspecto doentio, o que é um correlato

\footnotetext{
2 Isso deve servir também para analisarmos as oposições de Nietzsche em relação à Schopenhauer, que também pode ser vista como uma disputa teórica agonal do gênero enunciado na obra A filosofia na época trágica dos gregos. Em questões desta natureza dificilmente se chega a uma vitória definitiva, o que importa mais é manter a questão viva através do debate.
} 
do modo como Nietzsche interpreta a doença orgânica e também, por exemplo, o antissemitismo, considerado por ele um produto desse excesso de especialização e potencialização de impulsos unilaterais e que, em termos psicológicos, poderíamos chamar de "horror à diferença". Isto, portanto, geraria tanto o desequilíbrio social, como a doença orgânica. ${ }^{3}$

No entanto, desde a consideração do impulso apolíneo e do impulso socrático não se pensa propriamente em uma tendência primordial para a morte, nos moldes de Freud e de acordo com as concepções originais de Schopenhauer (apesar de que este não nomeie propriamente um impulso à morte). Em Nietzsche, tal tendência é sempre uma ação renovadora do impulso à potência a partir de um estado de decadência anterior, como no caso de Sócrates (que representaria uma versão decadente do grego trágico), ou como elemento constitutivo de um processo de alteração no equilíbrio de forças, como no caso de suas teses sobre a Vontade de potência. Ao final, talvez estejamos nos atendo a uma simples questão de nomenclatura, a não ser por um aspecto fundamental, que é o das acentuações de caráter moral, e não em relação às teses de fundo, que exigem, em qualquer caso, a renovação da vida e a certeza da morte. Vida e morte são fatos do indivíduo em nossos três autores. 0 problema está alhures.

A ordem subjacente à descrição do impulso socrático é a do excesso, da unilateralidade, exatamente como aparece o além-do-homem na descrição de Freud. Tal impulso quer se tornar instinto, e, de coisa secundária, transformar-se em coisa primária. Ele não admite alvos concorrentes e a dialética é a arma utilizada para a sua afirmação exclusiva e para a consequente despotencialização dos impulsos concorrentes.

Nietzsche é tomado por certo espanto diante dessa curiosa tentativa de reversão do impulso (Trieb) em instinto (Instinkt), tanto que este último termo adquire na sua obra um caráter eminentemente irônico. Para Almeida (2005), a noção de instinto é usada contra Sócrates, no capítulo 13 de $O$ nascimento

\footnotetext{
3 Isso nos remete às teses schopenhauerianas sobre a saúde e a doença consideradas a partir dos graus de exposição da matéria, que serão retomadas também por Freud em Além do Princípio de Prazer (1920) e leva o psicanalista aos conceitos de pulsão de morte e de vida.
}

da Tragédia, justamente porque o filósofo condena o instinto quando, por exemplo, fala de práticas exercidas apenas instintivamente. Essa é, pelo contrário, justamente a forma como Nietzsche enxerga o próprio socratismo, ou seja, como um movimento do pensamento em que predomina cega e rigidamente a racionalidade como um instinto degenerado. Nesse sentido, o termo adquire um caráter "nitidamente pejorativo" ao ser aplicado a Sócrates, pois não se trata do instinto "enquanto expressão das forças artísticas da natureza que apontam para a exuberância, a fertilidade e a afirmação da vida, mas, antes, de algo estático, mecânico e rígido" (Almeida, 2005).

Desse modo, o impulso ou instinto socrático aproxima-se de uma visão deformada do Kunsttrieb (impulso artístico) das abelhas e das aranhas, e é metaforizado na visão dos "domos conceituais" que aparecem descritos em Sobre verdade e mentira:

Pode-se muito bem, aqui, admirar o homem como um gênio construtivo, que consegue erigir sobre fundamentos móveis e como que sobre água corrente um domo conceitual infinitamente complicado: - sem dúvida, para encontrar apoio sobre tais fundamentos, tem de ser uma construção como que de fios de aranha, tão tênue a ponto de ser carregada pelas ondas, tão firme a ponto de não ser espedaçada pelo sopro de cada vento. Como gênio construtivo o homem se eleva, nessa medida, muito acima da abelha; esta constrói com cera, que recolhe da natureza, ele com a matéria muito mais tênue dos conceitos, que antes tem de fabricar a partir de si mesmo (Nitzsche, 1978).A concepção de uma racionalidade baseada na vida pulsional, como uma de suas manifestações, nos leva a uma região limítrofe entre a especialização instintiva e a liberdade de alvos do impulso. Isso mostra que uma das facetas da repetição, isto é, do modo como as coisas subsistem na natureza através da recorrência, dá-se na própria forma como se articulam as forças, que apenas têm uma aparência de leis, mas que na verdade, como escreve o filósofo, apropriam-se de todas as leis enquanto exercem a própria potência.

A menção às forças artísticas da natureza mostra que nela as tendências instintivas estão a serviço da criação do mundo, e não o inverso. Isso é interessante do ponto de vista analítico, pois é a isso que é conduzida a interpretação, ou seja, a servir como 
ferramenta para a autotransformação de um indivíduo ciente do caráter indeterminado e desejando ser o criador da própria existência, nos limites possíveis ao mundo humano e à transitoriedade inerente à vida orgânica.

A vontade de potência não apenas tolera resistência, mas a requer, a deseja, a busca. Se, em Freud, a inibição pode resultar tanto no sucesso do recalque e com isso simbolização, refinamento, ausência de sofrimento e sublimação dos alvos através de deslocamentos satisfatórios, pode também, por outro lado, resultar em algo excessivo, levando ao sintoma psíquico, à angústia e ao mal-estar no ambiente social.

Mas, mesmo aquela sublimação que evita o desprazer psíquico, recebe a ressalva de ser um modo de satisfação bastante tênue se comparado à satisfação direta, que permite descarga plena do impulso. Em Nietzsche, a resistência é, pelo contrário, eminentemente lúdica. Ela perpetua o jogo da vida. A própria definição de vida dada nos fragmentos póstumos corrobora essa tese.

Para o filósofo da Vontade de potência, a vida é "uma forma duradoura dos processos das fixações de força em que os diversos combatentes crescem desigualmente". Esse embate é a própria dinâmica vital, onde eventualmente se manda e eventualmente se obedece, e mesmo o obedecer é um comandar a si mesmo, o que é coerente com a visão do masoquismo como um sadismo invertido que aparece na Genealogia da moral, e, aliás, no próprio comandar já está implícita a resistência ao comando: "Obedecer e comandar são formas do jogo da luta" (Nietzsche, 1999).

Segundo Moura (2005), já está na estrutura fundamental da Vontade de potência a consideração de uma inibição fundamental: "Digamos que o conceito comporta dois momentos, a própria ambição, que é ambição de potência, e a limitação dessa ambição pela oposição de uma potência determinada, que busca ampliar-se e também ambiciona uma potência maior" (Moura, 2005).

Assim, nessa espécie de jogo de oposição e complementaridade entre comandar e obedecer pode ser pensado, em certa medida, um masoquismo fundamental, exatamente pela parte de restrição que cabe a todo impulso que ambiciona. Era exatamente essa a crítica de Schopenhauer ao querer-viver, no que ele implica de sofrimento e de fazer sofrer (seríamos ora "demônios atormentados" e ora "demônios atormentadores"), e por isso também a moral da compaixão.

Para Nietzsche, pelo contrário, trata-se de afirmar inclusive a perspectiva do sofrimento (o que não significa desejar o sofrimento, mas aceitar a parte de sofrimento que nos cabe), tendo em vista os estados de superação que toda Vontade de poder ambiciona. Esses estados de superação precisam estar por todos os lados, e pressupõem a perpetuação do jogo de forças: "A luta é cura, salvação". Como se diz em inglês, "run for your life"...

Há um comentário de Fonseca (2007) acerca dos Cinco prefácios para cinco livros não escritos que parece seguir a mesma direção. A autora menciona que nessa obra, ao discutir a função da ira no mundo grego, bem como também da sexualidade, da velhice, da morte e da mentira, vê-se a exaltação do conflito, e não há o elogio da vitória ou da derrota, que apenas fixariam hierarquias momentâneas: "No elogio ao combate, à competição, à luta pela doutrina órfica, os impulsos são considerados legítimos". Segundo a leitura da autora, "não se trata de combater a morte, mas de enaltecer a vida, da qual os instintos são inseparáveis" (Fonseca, 2007).

Freud, por sua vez, considera que as possibilidades de satisfação direta ou de sublimação são restritas em face das resistências inconscientes à mudança e da tendência do impulso em repetir estados de satisfação alcançados anteriormente. 0 Trieb freudiano é eminentemente regressivo: "A pulsão (Trieb) recalcada jamais renuncia à sua completa satisfação", a qual consiste numa experiência primária de satisfação. "Todas as formações substitutivas ou reativas, bem como as sublimações, são insuficientes para remover sua tensão contínua" (Freud, 2006).

Desse modo, percebe-se que Freud, num duplo movimento, aceita a ideia de Nietzsche de que a sublimação é um refinamento do alvo pulsional, mas reafirma simultaneamente a ideia schopenhaueriana de que o sofrimento é o fundo de toda a vida, pois a tensão constante do impulso é justamente o fenômeno que nos impele adiante: É da diferença entre o prazer efetivo obtido pela satisfação em relação ao prazer esperado que surge o fator que impulsiona (treibende). Este não permite que o organismo estacione em nenhuma das formas de satisfação anteriormente estabelecidas, mas, ao contrário, fará com que esse organismo, em seu contexto psíquico, reivindique um estado de satisfação profunda que, no entanto, é impedido tanto pela força das 
resistências que o processo de recalcamento mantém ativas, quanto também pelas dificuldades inerentes ao convívio humano.

Nietzsche, por sua vez, também considera as resistências psíquicas, mas, coerente com sua visão dionisíaca da vida, apenas tira delas a ênfase no sofrimento, entendendo que o impulso deseja o que lhe resiste tanto quanto o seu alvo, tornando através da resistência, a satisfação mais prazerosa (o que, aliás, corresponde com a descrição freudiana do mecanismo interno à sexualidade). Parece um processo de obtenção de prazer que confere um caráter primário ao sadomasoquismo, tendo o prazer como fato originário, um prazer derivado do sentimento de potência, enquanto em Freud e Schopenhauer ocorre o contrário: Neles, o além-do-homem é visto com certo ceticismo, e não como possibilidade redentora. 0 gênio e o asceta, em Schopenhauer, assim como as limitações do prazer e da sublimação em Freud, são possibilidades restritas e dependentes de características constitucionais do psiquismo. Em Freud sequer há uma possibilidade de negar o impulso que não venha a resultar simultaneamente em um retorno do recalcado, na forma de uma satisfação substitutiva.

Para Freud, o influxo mútuo entre tendências opostas e autocontraditórias é próprio ao caráter dos Triebe. Os dois modos da libido são pensados nesses mesmos termos de afirmação e limitação recíprocas. No entanto, a fisiologia dos impulsos envolve necessariamente a tensão desprazerosa vinculada ao acúmulo de estímulos internos que antecede a tentativa de descarga - se essa descarga, ao ocorrer, implica em afirmação, a inadequação dessa afirmação em relação ao princípio de realidade, por exemplo, gerará desprazer psíquico. Em Nietzsche, a mesma coisa. Porém, o que é ressaltado é o prazer da afirmação, que pressupõe um desprazer, que deverá ser afirmado conjuntamente, na medida em que se afirma com isso a própria vida.

Note-se, nesse caso, que tanto Freud como Nietzsche se relacionam o tempo inteiro com a estrutura da Metafísica da natureza de Schopenhauer, independente do nível de contato específico e do modo de aproximação de cada um, considerando-se que a hipótese da afirmação da vida é contraposta à negação no capítulo 54 de $O$ Mundo como Vontade e Representação. A ênfase dada a certas características identificadas nos impulsos e na ausência de fundamentação última para o desejo exigirá um redimensionamento da consciência, seja do ponto de vista puramente intelectual (a consciência como Bewußtsein), seja moral (a consciência como Gewissen). Ao final, a tensão entre os pensamentos éticos e estéticos, e sua prevalência, resultará nas diferenças que observamos e que, no fundo, são interpretações necessariamente complementares e não necessariamente excludentes.

\section{A dependência mútua entre fisiologia e psiquismo}

0 enraizamento da fonte do impulso no organismo e as consequências dessa conexão do psíquico com o orgânico é um dos aspectos que mais nos chama a atenção na relação entre as concepções estudadas. Em Freud, como cientista da natureza, muito mais ainda.

Para Freud, por exemplo, as pulsões (Triebe) são numerosas e emanam de grande variedade de fontes orgânicas, atuam de modo independente umas das outras e só alcançam a capacidade de síntese no decorrer do tempo em função de uma organização específica da libido. A finalidade pela qual cada pulsão isolada luta é o prazer de órgão, e a síntese é alcançada apenas quando advém a função reprodutora, isto é, eles encontram na sexualidade reprodutiva uma finalidade comum ainda que ela não seja garantida.

O caminho em direção aos diferentes objetos determinados nas pulsões parciais é caracterizado pela irregularidade e pela incompletude. Tudo pode falhar ou acontecer de um modo diferente.

A fonte, pelo contrário, produz estímulos de modo incessante, que se acumulam na ausência da oportunidade de satisfação e precisam ser descarregados de alguma forma. Nesse caso, ocorre a passagem do plano fisiológico ao plano psíquico.

Em Schopenhauer, por sua vez, o organismo é o representante fenomênico da Ideia platônica (que hoje substituímos confortavelmente pelo DNA, um conceito que exprime a Ideia do ser de um ponto de vista material e que Schopenhauer provavelmente entenderia que corrobora biologicamente o seu pensamento metafísico, segundo o modelo de Sobre a Vontade na Natureza, que constitui o seu caráter inteligível, e que por sua vez, é a expressão da 
Vontade que em si mesma está completamente fora da Representação. ${ }^{4}$

o Trieb, nessa ordem de coisas, é o representante de uma tendência do caráter e a expressa se impondo frente às outras tendências que compõem o mesmo caráter originário. Isso configura o conflito interno da Vontade no âmbito do psiquismo e determina o sofrimento psíquico tanto pela impossibilidade de satisfazer a demanda do organismo por satisfação, quanto pela disputa entre tendências antagônicas, que nos fazem carentes e cindidos entre diferentes alvos e objetos. 0 pensamento sobre a fonte (Qüelle) do impulso (Trieb) apresenta, portanto, na filosofia de Schopenhauer, uma função integradora em relação aos conceitos ligados à exposição fenomênica da Vontade, isto é, trata-se de um instrumental teórico para explicar a própria metafísica da natureza. Em contraste com isto, o objeto tem uma função ilusória, enganosa (há nisso uma antecipação clara da ironia lacaniana em relação à função do objeto, que se opõe à visão de Nietzsche a respeito). Ao mesmo tempo em que a fisiologia do impulso exige um objeto qualquer, e esse objeto não precisa ser propriamente real, mas sim apenas efetivo para o psiquismo (por isso também a expressão freudiana "realidade psíquica", que tem o mesmo sentido).

A Representação em geral apresenta o caráter de uma fantasmagoria, ao fundo da qual subjaz a única e irrepresentável realidade (o "Real" lacaniano): o sentido da fonte dos impulsos, que em si mesmos e no seu conjunto não podem ser fundamentados, pois representam a vontade do corpo, que, por sua vez, corresponde ao inexprimível querer metafísico. Essa vinculação do querer orgânico a um querer metafísico é um ponto tenso entre Schopenhauer e Nietzsche. Como o querer schopenhaueriano é sem fundamento, torna-se inútil tentar satisfazê-lo. Isto é, o que faz do impulso um impulso alcança um limite de sublimação, como vemos também em Freud, inclusive serve como advertência aos psicanalistas em relação às resistências em análise. Retomando o que escreve Schopenhauer, é só

4 Explicações desse aspecto específico da Filosofia de Schopenhauer podem ser encontradas em diversos pesquisadores, mas recomendo a leitura do livro de Maria Lucia Cacciola, Schopenhauer e a Questão do Dogmatismo, de 1994. através da compreensão intrínseca do fenômeno circular da vontade orgânica que se torna possível, apenas momentaneamente, através da arte, cessar o movimento em torno dos objetos, contemplando o mundo do desejo objetivamente, e não mais como parte interessada. Esse efeito quietivo (quietiv) da contemplação, especialmente da arte, é visto por Nietzsche como uma necessidade psicológica de Schopenhauer, e não como uma propriedade geral da experiência artística; muito pelo contrário, ele a via como um convite à felicidade.

Em Nietzsche, a relação dos Triebe com a carência foi exposta na metáfora dos lobos famintos. 0 impulso está sempre à espreita e aproveita toda oportunidade para se satisfazer. Nietzsche pensa o regime de alimentação dos impulsos como o modo pelo qual as tendências parciais, os lobos famintos, alcançam hegemonia e mantém outras subordinadas ao seu poder relativo e momentâneo. À diferença do que vemos em Schopenhauer, a luta por satisfação e a resistência mútua entre impulsos nela implicada são também partes constituintes do regime de alimentação, sendo, portanto, também desejadas. A hegemonia de um impulso sobre outros é episódica, e essa transitoriedade é o modo pelo qual a Vontade de Potência universalmente se organiza para manter a vida e o desejo a ela ligado.

Em Nietzsche, todo o sofrimento de fundo ligado à fonte dos Triebe é despotencializado e se transforma em prazer de disputa. No âmbito da vida humana consciente, vemos o homem nietzschiano em uma condição trágica, mas esta aparece sob uma leitura diferente, pois não implica em resignação frente ao destino. Se a consciência nunca abrange a natureza das intenções do psiquismo inconsciente, do mesmo modo que o sofrimento do organismo no mundo provém da inconstância do objeto de satisfação, há no inconsciente uma constante produção de alternativas (o que tem importância clínica e deve ser meditado pelo psicanalista contemporâneo e pelos psicólogos em geral), que renovam a vida e são meios de afirmação da Vontade de potência. A sua forma de apreciação da solução indicada por Schopenhauer para o problema de um Querer (wollen) que se renova constantemente indica, por um lado, a plasticidade do impulso e, por outro, reafirma a necessidade de que as alternativas de satisfação no âmbito do desejo devam corresponder à situação anterior do conjunto de impulsos que formam aquela vontade. 
Basicamente, se a afirmação da vontade depende de um quietivo, de uma anestesia parcial, esse será também o caráter da sublimação.

A forma básica desse mecanismo já é indicada em $O$ nascimento da tragédia, pois nesse livro a função da arte em geral e, nomeadamente, a função da tragédia, é envolver o rosto terrível da existência sob uma máscara bela, para que o trágico possa ser sublimado e ocorra uma correspondente facilitação de caminhos. Os impulsos que correspondem a Dioniso e Apolo são inseparáveis em função da necessidade de dominar o excesso de estímulos, transformando o terrível ligado à natureza humana em algo apreciável e novamente desejável. Essa função estimulante da arte corresponde ao caráter sublimatório do impulso, que se esconde inclusive sob a negação, pois para ele não é possível negar, apenas afirmar a negação, o que é também um ato da Vontade de potência. Esse caráter ilusório do movimento sublimatório é depreciado por Schopenhauer e apreciado por Nietzsche, encontrando-se na raiz do perspectivismo ligado a esta filosofia. Se em Schopenhauer o querer-viver é denunciado como um ardil que impede ao intelecto ter a visão do sofrimento objetivo da vida, em Nietzsche a ilusão também afirma a vida, mas é desejada enquanto afirmação justamente porque leva a vida adiante. Nesse sentido, a Vontade de potência se afirma invariavelmente, enquanto a Vontade postulada por Schopenhauer alcança, através do Gênio e do Asceta, o autoconhecimento, e percebe a recorrência intrínseca à sua atividade como algo a ser negado (o que não implica na supressão da vida, isto é, no suicídio, mas sim numa atitude de negação radical do desejo à maneira dos cínicos gregos e dos estoicos, bem como corresponde também à postura das antigas religiões orientais caras ao filósofo da vontade).

Nesse modo de entender o problema do Trieb humano, o sentido da autossuperação é a própria anulação do desejo reconhecido em sua circularidade demoníaca. 0 próprio Freud aponta para o caráter demoníaco dos impulsos, na medida em que eles contrariam os ideais da consciência ligada à linguagem e à cultura. A dificuldade da consciência está em reconhecer e enlaçar esses impulsos, que são vistos então como algo exterior e maléfico, com tudo o que há de estranho e inquietante nisto. A crítica de Nietzsche a Schopenhauer não se dá no plano do reconhecimento do impulso como este elemento pretensamente demoníaco, mas sim na persistência da consideração do mal desde uma perspectiva cristã, e por isso a moral da compaixão é condenada pelo autor de Além do bem e do mal. Tal crítica pode ser estendida parcialmente a Freud, especialmente aos textos anteriores a 1910, nos quais o caráter da sublimação parece corresponder parcialmente a uma dessexualização do impulso no sentido schopenhaueriano.

Nos três autores vemos duas situações distintas compondo o mesmo fenômeno. A primeira situação é relativa à força do impulso ou pulsão, seu ponto de partida em uma fonte orgânica e sua constante atividade de carga e descarga. Considera-se também que não se trata de um único indivíduo, mas de uma miríade de indivíduos desejantes, todos lutando por satisfação de suas carências, sofrendo e produzindo sofrimento alheio. A segunda e distinta situação é relativa aos alvos (Zwecke) e objetos (Objekte) do impulso. Aqui está um campo muito diferente em comparação à fonte, pois tudo precisa adquirir significado a posteriori, e para isso depende do modo como a linguagem e a experiência da diferença foram vivenciadas por indivíduos e por grupos de indivíduos ao longo do tempo. 0 objeto não é dado a priori, como no simples instinto. Ele precisa ser constituído, mantido, e nada o garante de antemão, pois ao contrário da constância da força que o exige, o objeto se caracteriza pela possibilidade permanente não só da falta real, como diríamos em linguagem lacaniana, mas também da perda de sentido e de valor enquanto objeto de satisfação. Esse objeto, seja ele qual for, não é constante como a demanda, e por isso a necessidade de cuidados para garantir a sua presença que, no entanto, não pode ser garantida.

Outra concepção de permanência sob as mudanças, também ligada à força e, portanto, à fonte $\mathrm{e}$ não ao objeto, está relacionada também ao contexto da segunda teoria dos impulsos, adquirindo ali um novo e complementar significado que aproxima mais ainda Freud desse diálogo entre as obras de Schopenhauer e Nietzsche.

\section{A análise do significado e do valor da destrutividade}

Os conceitos de compulsão à repetição e pulsão de morte não são nomeados nas filosofias 
de Schopenhauer e de Nietzsche, mas esses dois autores, como Freud, analisam o que significaria a morte e a regularidade fisiopsicológica dos impulsos conectados à noção de processo inconsciente. Já o conceito de sublimação dos alvos pulsionais aparece nomeado em cada um deles como uma resposta ao problema da satisfação e de seu vínculo inevitável com o sofrimento. Ele resulta em questões éticas e é nomeadamente a justificativa da clínica de Freud. 0 que há de comum entre os autores, num primeiro momento, é o aspecto fisiopsicológico: o deslocamento do processo consciente para uma posição secundária e a identificação da verdade desse inconsciente em suas relações de intensidade, nomeadamente nas questões relacionadas ao sofrimento e ao prazer.

O conjunto de consequências extraídas desse modo básico de encarar o psiquismo com todas as suas implicações para o indivíduo e para a cultura representam um "golpe narcísico" para a humanidade: não há um governo racional da existência, não estamos no centro do universo e nem mesmo a consciência está no centro da vida psíquica. Além disso, entre os filósofos sequer há um consenso em relação ao problema dos valores vinculados ao conjunto da existência.

Vida e morte estão no centro da análise dos valores levantada por Nietzsche contra os filósofos que o antecedem, e especialmente como reação e emancipação em relação ao filósofo da Vontade. Para ele, o querer sem a direção e o governo da inteligência, privado de toda reflexão, aparece como uma "cega (blinde), impetuosa (ungestüme) e destruidora força natural (zerstörende Naturkraft)", um "cavalo (Rosse) que derrubou (abgeworfen hat) seu ginete (Reiter)", um "relógio (Uhr) cuja mola saltou de repente (herausgenommen)", "um rio (Strom) cujo dique (Damm) tenha sido rompido (durchbrochen)", como ele descreve na parte final do capítulo sobre a loucura dos Suplementos ao livro O Mundo como Vontade e Representação (Schopenhauer, 1986, p. 518).

Inversamente, a sublimação corresponde ao gradual predomínio da inteligência sobre as tendências mais diretas de satisfação dos impulsos provenientes, em última instância, do querer, não apenas originado no organismo, mas que é, em síntese, o próprio organismo. A sublimação é polêmica entre os autores exatamente pelo modo como Nietzsche retoma a metafísica do belo de Schopenhauer, combatendo as noções de contemplação desinteressada e de gênio, e também o ponto de vista moral fundamentado na compaixão, e em cujo extremo Schopenhauer põe a figura do asceta como aquele através de quem a Vontade nega a si mesma.

Voltando às citações transcritas acima, vemos que apesar de se referirem ao tema da loucura e não ao da morte, mostra-se realçada a característica destrutiva do querer-viver em estado bruto, mostrado como egoísta e unilateral. 0 ajuste das vontades humanas, seja pelo processo civilizatório em geral, seja pelo Estado-focinheira que existiria para conter esse animal de rapina que é o homem, na opinião de Schopenhauer, é semelhante ao que ocorre também nos outros fenômenos da natureza, pois ao fundo da aparente harmonia de plano está o conflito permanente, só que com um acréscimo de inteligência que impõe à História humana uma forma de crueldade sádica e racional que inexiste no conjunto da natureza.

A destrutividade inconsciente característica da vida natural é percebida também no interior do próprio psiquismo, o que acaba sendo, pode-se dizer, uma espécie de masoquismo originário, como é cogitado por Freud.

As vontades fenomênicas do carrasco e a da vítima são uma única e mesma Vontade, mas também no íntimo do organismo há vítimas e carrascos representados pelos Triebe, autodivergentes em constante disputa por meios de obter satisfação. Essa identificação entre carrasco e vítima tem um sentido metafísico na unidade da Vontade e um sentido fenomênico oposto, pois do ponto de vista da representação, a identificação expõe a desunião da Vontade consigo mesma, reflexo da própria individuação. Desse modo, do ponto de vista da pulsão de morte (Todestrieb), ela está além da tendência de retorno ao inorgânico, e deve ser encarada também como destrutividade. Em Schopenhauer, isso é fundamental para se entender o jogo entre afirmação (Bejahung) e negação da Vontade de vida (Verneinung des Willens zum Leben).

É necessário adotar esse conhecimento da vontade humana como essencialmente cindida, destrutiva e autodestrutiva, para que se possa com isso, de fato, afirmá-la. Nesse sentido, tudo se passa exatamente como em Nietzsche. E tudo isso está conectado às meditações de ambos acerca do mundo grego e especialmente a referência que fazem a Empédocles de Agrigento. Nas Extemporâneas, 
o próprio autor de Schopenhauer como educador mostra que em certo momento reconhece essa via do pensamento schopenhaueriano: "afirmas (bejahst) então, do fundo do coração, essa existência? Ela te basta? Queres ser seu porta-voz, seu redentor? Pois basta um único sim! Verdadeiro de tua boca - e a vida, tão gravemente acusada, estará absolvida" (Nietzsche, 1978, p. 73). Nietzsche dá a entender nesse momento em que ainda não rompeu com o Educador que por trás do pessimismo teórico de Schopenhauer há um caráter prático e racional, identificado a Empédocles de Agrigento, tal como Freud também admitia. Basta, para perceber a conexão, a leitura de Análise terminável $e$ interminável e certos comentários de Nietzsche sobre Schopenhauer (Nietzsche, 1999, p. 818) e Empédocles (Nietzsche, 1985, p. 245-247). 0 ponto de vista que visa enlaçar o terrível da existência, exposto na visão repetitiva do conjunto de forças cósmicas, e especialmente no caráter demoníaco da compulsão à repetição, expõe o indivíduo humano à questão da transitoriedade e de sua afirmação.

Inversamente, o ponto de vista da negação da Vontade passa necessariamente por uma sublimação do querer e dos impulsos como seus representantes psíquicos, expostos no sentimento do corpo como objeto. $\mathrm{O}$ ponto controverso dessa relação entre o querer e os objetos reais, dentre os quais figura o próprio corpo, é o de que seja possível ou desejável uma sublimação do querer ao ponto de que ele desapareça, ainda que momentaneamente. Para Nietzsche, assim como para Freud, trata-se de uma sutilização e não de uma "nadificação". Desse modo, mesmo quando se nega, afirma-se alguma coisa.

Para ter claro o sentido dos dois pontos de vista em Schopenhauer, voltemos ao que ele diz no capítulo 54 de $O$ Mundo como Vontade e Representação:

A Vontade afirma a si mesma (bejaht sich sel$b s t$ ), significa (besagt): quando em sua objetidade, ou seja, no mundo e na vida, a própria essência lhe é dada plena e distintamente como representação, semelhante conhecimento não obsta de modo algum seu querer, mas exatamente esta vida assim conhecida é também enquanto tal desejada; se até então sem conhecimento, como ímpeto cego, doravante com conhecimento, consciente e deliberadamente. - 0 oposto disso, a negação da Vontade de vida, mostra-se quando aquele conhecimento leva $o$ querer a findar, visto que, agora, os fenômenos particulares conhecidos não fazem mais efeito como motivos do querer, mas o conhecimento inteiro da essência do mundo, que espelha a Vontade, e provém da apreensão das Ideias, torna-se um quietivo (Quietiv) da Vontade e, assim, a Vontade suprime a si mesma livremente (der Wille frei sich selbst aufhebt). (Schopenhauer, 2005, p. 369-370)

O quietivo, no caso, está em relação ao objeto de satisfação direta do impulso, correlato do egoísmo individual e coletivo da humanidade. A filosofia nietzschiana expressa um ponto de vista admitido por Schopenhauer nessa descrição do princípio afirmativo, intelectual e prático. Por outro lado, os mesmos conhecimentos levam também ao abrandamento e, no extremo, à supressão do querer na consciência, e parecem determinar em seu conjunto a determinação do fenômeno da vida do ponto de vista intelectual e teórico. Por seu lado, Nietzsche não refuta a possibilidade da negação psicológica, mesmo a mais veemente, como se observa, por exemplo, no melancólico, mas supõe que ela seja simplesmente o reflexo de um querer que nega. Em psicanálise, isso caracteriza a retirada do investimento libidinal, não a supressão da libido.

Para Schopenhauer, a vida, assim como a morte, aparece - frente à intuição intelectual e ao pensamento do filósofo que elabora o conhecimento da experiência - como aspecto ligado ao ponto de vista da representação, e não diz respeito à Vontade fora do fenômeno. 0 indivíduo, Vontade objetivada enquanto determinado caráter orgânico, deve se sujeitar não apenas a sucumbir por milhares de razões diferentes, por meio "dos acasos mais insignificantes", mas já é "originariamente" (ursprünglich) determinado (bestimmt) a isso, e levado a desaparecer pela própria natureza desde o instante em que tenha servido à conservação da espécie (Erhaltung der Gattung)" (Schopenhauer, 2005, p. 359). Se o amor sexual, como escreve Barboza (2000) é a "manifestação mais direta da essência do mundo", do querer-viver insaciável, a morte é a sua contrapartida e representa o "mero desaparecimento do organismo gerado no ato sexual". No âmbito do mundo como representação, vida e morte representam incessantemente um "drama cósmico" chamado existência, um mundo cindido pelo próprio fato de que a Vontade é essencialmente repetição 
(Wiederholung) e autodiscórdia: São sempre "as mesmas personagens, com igual intenção e igual destino" (Schopenhauer, 2000).

0 caráter de repetição está exposto em diversos níveis: 1) no caráter da Vontade como coisa-em-si, destituída de conhecimento, que é apenas um "ímpeto (Drang) cego (blinder) e irresistível (unaufhaltsamer)", como a vemos aparecer na natureza inorgânica e vegetal, assim como nos aspectos vegetativos do nosso próprio organismo e na vida dos impulsos que nos chegam à consciência; 2) a vontade exposta em fenômeno sempre quer a vida, e por isso chega a ser um "pleonasmo" (Pleonasmus) falar em vontade de vida. Mas a vida humana exige geração, isto é, repetição do mesmo; por conseguinte, também a morte. Vida e morte são, portanto, correlatos que se afirmam e suprimem mutuamente com igual necessidade; 3) a repetição se dá no caráter imortal da espécie enquanto ideia, pois apenas ela, e não os indivíduos, tem realidade propriamente dita; 4) a repetição se dá no indivíduo enquanto manifestação de um mesmo caráter inteligível ao longo de toda a vida, não importa a que sorte de vicissitudes e adaptações seja obrigado, o que dá a esse caráter uma implacável tendência regressiva, caracterizada na vida do impulso como diferentes formas de expressão constantemente oscilando em torno de um mesmo eixo gravitacional, que ao mesmo tempo exprime formas perenes e transitórias, ou adquiridas. 5) o tempo da vida é sempre o presente: "Podemos comparar o tempo a um círculo que gira incessantemente". Nessa imagem, "a metade sempre a descer seria o passado, a outra sempre a subir seria o futuro". Acima, porém, "o ponto indivisível que toca a tangente seria o presente inextenso". Conclui dizendo que "assim como a tangente não toma parte do movimento circular, tampouco o presente, o ponto de contato do objeto cuja forma é o tempo, toma parte no sujeito, que não possui forma alguma, pois não pertence ao cognoscível, mas é condição de todo cognoscível". Dito de outro modo, "o tempo é como uma torrente irresistível e o presente uma rocha contra a qual ele se quebra, sem, no entanto, poder arrastar a esta" (Schopenhauer, 2000).

Deste modo, o presente é a única forma da vida real, a única forma na qual a Vontade aparece. 0 tempo que vemos passar é ilusório e vinculado à representação como forma da finitude, que não atinge nem a Vontade como coisa em si e nem o sujeito do conhecimento (Schopenhauer, 2000).
Deparar-se com o problema da morte individual não parece a Schopenhauer tão estranho e inaceitável; pelo contrário. Ao comentar sobre a complementaridade entre vida e morte, ele escreve que "a natureza não se entristece" (Schopenhauer, 2000). Aliás, a necessidade de elaboração psíquica da questão da morte é pensada por ele a partir do fato de que o homem é a natureza mesma, que por sua vez é apenas a objetivação do querer-viver. Para ele, o homem, dotado de razão, pode superar o egoísmo, e com isso ser capaz de encarar as coisas sob o prisma da participação do indivíduo no todo. Pode também, com justa razão, se consolar com a própria morte e com a de seus entes queridos, do ponto de vista puramente objetivo e de acordo com a existência fenomênica, pois sabe que a vida é, em toda parte, apenas uma contínua alteração da matéria, da qual advém tanto a transitoriedade individual, quanto a imortalidade da espécie.

Vida e morte formam uma espécie de corrente alternada na qual ocorrem muitas pequenas mortes e pequenos nascimentos: "A alimentação e a reprodução contínuas são diferentes da geração tão-somente segundo o grau, assim como a excreção contínua é diferente da morte apenas segundo o grau". Por conseguinte, "assim como estamos a todo momento contentes em conservar a forma, sem lamentar a matéria perdida, também temos de nos comportar do mesmo modo quando na morte ocorre o mesmo, porém numa potência mais elevada e no todo, que aquilo que ocorre a cada dia e a cada hora no particular com a excreção" (Schopenhauer, 2000). Assim como não nos perturbamos com as pequenas mortes do funcionamento orgânico, também não devemos tremer diante da morte em tom maior.

Ora, se é próprio do vivente buscar inexoravelmente a sua morte, o que resiste a ela é meramente a consciência intelectual capaz de abstrações a respeito do passado e do futuro. A nossa consciência racional é prática, e via de regra não se apercebe que a matéria de nosso organismo é constantemente renovada através de pequenas mortes e pequenos nascimentos, dentro do mecanismo de controle vegetativo exercido pelo querer-viver, que em última instância depende dos impulsos contrários, tanto no âmbito do próprio organismo, quanto no âmbito da espécie, que renova seus organismos da mesma forma para se manter perene. Esses são problemas que exigem reflexão maior e excedem os interesses práticos do intelecto. 
Também o problema da autossupressão é assimilado no contexto da própria Vontade como uma afirmação dela, ao contrário do que se poderia supor considerando meramente o interesse do organismo, o que designa uma potencialização de um fenômeno inerente a ela mesma no contexto da individuação, tratado pelo filósofo no contexto do egoísmo. Essa é a questão propriamente metafísica em torno do masoquismo e do suicídio.

A pista para se compreender a influência de Schopenhauer sobre Freud é a maneira como ele parte de uma teoria que considera a libido como correlata da sexualidade, em uma linha de pensamento que corresponde à nietzschiana, e passa, depois, a partir de Além do princípio de prazer, a considerar dois modos da libido, um que afirma e outro que nega a vida, como vimos. É nesse âmbito que ressoa a questão da autodiscórdia da Vontade.

Como vimos no capítulo sobre Schopenhauer, os órgãos sexuais são o foco da Vontade. Já na introdução, dissemos também que Freud reconhece a prioridade de Schopenhauer como aquele que anuncia aos homens o seu ser sexual, tanto do ponto de vista da sexualização de todas as atividades humanas, como do ponto de vista da satisfação sexual como único alvo dessas atividades que resultam, em última análise, na perpetuação do homem através da geração. Do mesmo modo, Freud, ao se deparar com o tema da morte, percebe na filosofia de Schopenhauer praticamente a única literatura de referência a respeito, o que mostra o quanto esses dois temas humanos foram recalcados na cultura, apesar de sintetizarem o conjunto das preocupações humanas.

Ao tecer comentários a respeito da metafísica da sexualidade, Cacciola (1995) diz que a identificação da Vontade com o querer-viver denota seu caráter de impulso sexual. Escreve que, em Schopenhauer, "a sexualidade expande-se e amolda-se nas várias manifestações da vida afetiva e intelectual". Do mesmo modo, a Vontade exteriorizada ao nível humano, é um conceito que se recobre com o de sexualidade. Mas, como é apenas como organismo vivo que ela se manifesta desse modo, participa também, de modo mais simples, como fundamento do mundo inorgânico nas "forças que dominam a matéria". As forças naturais são como que um correlato inorgânico da sexualidade. Em contrapartida, a autora lembra que as considerações de Freud acerca da tendência conservadora dos impulsos, e, em especial, das tendências regressivas a elas inerentes, estão relacionadas ao que a autora chama de "história natural" de Schopenhauer, a saber, a hierarquia das Ideias na efetividade (Cacciola, 1995, p. 60).

Nessa hierarquia, o inorgânico representa os patamares inferiores escravizados pela forma superior que se objetiva como organismo e dele participa, apoiando, e ao final, retomando seus direitos, pelo que se explica a doença e também a morte: "As ideias mais perfeitas surgem, pois, do triunfo sobre as mais imperfeitas, cuja essência, no entanto, é mantida de modo subordinado". A fadiga e o sono são explicadas da mesma maneira. Ao final, a morte do organismo, isto é, aquela Ideia superior que subordina uma série de graus inferiores de objetivação da Vontade, significa "a vitória das forças naturais" e um "restabelecimento do estado inorgânico" (Cacciola, 1995). Desse modo, a matéria muda de forma através da luta entre os diversos graus de objetivação, o que mostra, como já vimos, o seu caráter cindido na experiência. Isso refuta completamente a tese de que a Vontade de Schopenhauer se reduziria a um substrato ontológico da efetividade, como aparece em Lacan e em certas passagens de Nietzsche. No entanto, como menciona Cacciola (1995), se Lacan entende a pulsão de morte como "vontade de recomeçar com novos custos, vontade de outra-coisa", (Cacciola, 1995), isso está perfeitamente de acordo com o querer-viver schopenhaueriano. Do mesmo modo, pensamos, esta é a mesma relação do querer-viver com a vontade de potência de Nietzsche, não como ele interpreta a vontade de vida, mas como Schopenhauer fala dela, isto é, como um conflito de forças atuantes num conflito sujeito à hierarquização. Se Nietzsche designa o impulso como "uma ânsia de domínio" (Art Herrschsucht), cada um com "a sua perspectiva, que gostaria de impor como norma a todos os outros impulsos" (allen übrigen Triebe) (Cacciola, 1995), como vimos, Schopenhauer, por seu lado, escreve que "cada fenômeno da Vontade, inclusive os que se expõem no organismo humano, travam uma luta duradoura". Defende também que em toda a natureza vigora, em toda a extensão do tempo, "luta, combate e alternância de vitória". Schopenhauer especifica ainda mais esta relação: "A Vontade de vida crava continuamente os dentes na própria carne" (an sich selber zehrt) (Schopenhauer, 2000). 
Para Nietzsche, se a Vontade é inseparável de seus alvos, as qualidades estão unidas em torno de um apetite fundamental. Como vimos, para esse autor o impulso originário e comum a todos os impulsos é o impulso ao poder. Todo impulso é vontade de potência. Considerando-se esta forma de argumentação, para este filósofo é fundamental considerar o sadismo como sendo coisa primária, pois poder e sadismo são correlatos, e o masoquismo é secundário, como agressividade que se volta contra si mesma no interior do psiquismo. Freud primeiro é partidário dessa Ideia e depois considera a possibilidade um masoquismo primitivo, o que está de acordo com Schopenhauer, para quem tanto o sadismo como o masoquismo representam polaridades da própria Vontade na individuação, cravando as garras na própria carne. Essa questão é crucial no embate entre os autores em relação aos valores éticos e estéticos. É nesse ponto de inserção que Freud pensará a questão do que se repete no inconsciente, entendendo que a repetição é efeito da tendência regressiva dos impulsos, que em última instância são tendências de retorno ao inanimado. Tal natureza íntima ao impulso tornará o psicanalista reticente em relação ao fim das guerras ou ao progresso da humanidade. Outra razão para isto é que o processo consciente é uma superfície ao fundo da qual ocorrem os fenômenos psíquicos primários, fora do controle da consciência e inacessíveis ao princípio de realidade. No entanto, Freud parece pender às posições de Schopenhauer em relação ao seu pessimismo fundamental, e até no modo como apenas secundariamente pensa na possibilidade de sublimação, ao contrário de Nietzsche, que acentua muito mais o apoio da destrutividade às formas de vida. Para viver é preciso morrer.

O caso do psicanalista vienense, no contexto desses dois filósofos, é particularmente curioso. Devido ao seu surgimento em meio a uma cultura que ainda estava digerindo aquelas obras, ele parece oscilar entre as suas concepções, até mesmo porque os dois filósofos já haviam antecipado, em grande medida, as descobertas clínicas da psicanálise, levando Freud a ignorá-los explicitamente para manter a sua independência de julgamento, o que mostra que não pôde ignorá-los realmente. Ao realizar esse movimento, ele naturalmente acaba aderindo às teses filosóficas, ainda que de modo muito particular e especialmente experimental.

\section{Referências}

Almeida, R. M. (2005) Nietzsche e Freud: eterno retorno e compulsão à repetição. São Paulo: Loyola.

Cacciola, M. L. M. O. (1994). Schopenhauer e a questão do dogmatismo. São Paulo: EDUSP.

Cacciola, M. L. M. O. (1995). A vontade e a pulsão em Schopenhauer. In A. A. S. Lima (Org.), As pulsões. São Paulo: Escuta/EDUC.

Fonseca, T. S. M. L. (2007). Nietzsche e a auto-superação da crítica. São Paulo: Humanitas.

Fonseca, E. R. (2012). Psiquismo e vida: sobre a noção de Trieb nas obras de Freud, Schopenhauer e Nietzsche. Curitiba: Editora UFPR.

Freud, S. (1999). Die S Freud-Studienausgabe [A Edição de Estudos de Sigmund Freud]. (Vols. 1-11, S. F. Verlag, org.). Munique: DTV/ de Gruyter.

Freud, S. (2006). Além do princípio de prazer. In Obras psicológicas de Sigmund Freud - Escritos sobre a Psicologia do Inconsciente (1915-1920). (Vol. 2, L. A. Hanns, trad.). Rio de Janeiro: Imago.

Freud, S. (1976). Moisés e o monoteísmo. In Obras completas (Vol. XXIII, 3. J. L. Etcheverry, trad.). Buenos Aires: Amorrortu Editores, p. 24.

Freud, S. (2006). Obras psicológicas de Sigmund Freud - Escritos sobre a Psicologia do Inconsciente (19151920). (Vol. 2, L. A. Hanns, trad.). Rio de Janeiro: Imago.

Freud, S. (1976). Obras Completas. (J. L. Etcheverry, trad.). Buenos Aires: Amorrortu Editores.

Lacan, J. (1994). A ética da psicanálise. In O seminário. (Vol. 7). Rio de Janeiro: Jorge Zahar.

Moura, C. A. R. (2005). Nietzsche: Civilização e Cultura. São Paulo: Martins Fontes.

Moura, C. A. R. (1995). As pulsões. São Paulo: Escuta.

Nietzsche, F. (1999). Kritische Studienausgabe [Edição crítica de estudos]. (G. Colli e M. Montinari, os.) Munique: DTV/ de Gruyter.

Nietzsche, F. (1978). Considerações Extemporâneas. In Os pensadores. (R. R. T. Filho, trad.). São Paulo: Abril Cultural.

Nietzsche, F. (1978). Obras Incompletas. In Os pensadores. (R. R. T. Filho, trad.). São Paulo: Abril Cultural. 
Nietzsche, F. (1985). Pré-Socráticos. In Os pensadores. (R. R. T. Filho, trad.). São Paulo: Abril Cultural.

Nietzsche, F. (2005). A visão dionisíaca do mundo. (M. S. P. Fernandes e M. C. S. Souza, trads.). São Paulo: Martins Fontes

Nietzsche, F. (1992). O nascimento da tragédia - ou helenismo e pessimismo. (J. Guinsburg, trad.). São Paulo: Companhia das Letras.

Nietzsche, F. (2004). Aurora. São Paulo: Companhia das Letras.

Nietzsche, F. (1978). Sobre verdade e mentira no sentido extra-moral. In: Os pensadores. (R. R. T. Filho, trad.). São Paulo: Abril Cultural.

Nietzsche, F. (2008). A filosofia na era trágica dos gregos. São Paulo: Hedra.

Schopenhauer, A. (2000). Uma filosofia do consolo (Jair Barboza, trad.). In Metafísica do amor, metafísica da morte, p VII. São Paulo: Martins Fontes.
Schopenhauer, A. (1986). Sämtliche Werke (Vols. 1-5, Wolfgang von Löhneysen, ed.). Frankfurt: Suhrkamp Verlag.Schopenhauer, A. Die Welt als Wille und Vorstellung, [0 Mundo Como Vontade e Representação] - 1819 (1a. Ed.), 1844 (2a. ed.); 1859 (3a.ed).

Schopenhauer, A. (2005). O mundo como vontade e como representação (J. Barboza, trad.). São Paulo: Unesp.

Schopenhauer, A. Die Welt als Wille und Vorstellung, Ergänzungen, [0 Mundo Como Vontade e Representação: Complementos] - 1844 (2 a. ed.); 1859 (3a. ed).

Schopenhauer, A. (2014). O mundo como vontade e representação: complementos. (E. R. Fonseca, trad.). Curitiba: Editora UFPR.

Schopenhauer, A. (1836). Über den Willen in der Natur [Sobre a Vontade na Natureza]. 